\title{
EVALUATION OF ETHNOBOTANICAL PLANTS USED BY THE MALAMUTHANS TRIBAL COMMUNITY IN THE MEDAPPARA FOREST, WESTERN GHATS OF KERALA
}

\author{
Anjana, P.R. and S. Paulsamy* \\ Department of Botany, Kongunadu Arts and Science College, Coimbatore. \\ *E.mail: paulsami@yahoo.com
}

\begin{abstract}
Medappara forest of Kerala was surveyed to list out the ethnobotanical plants used by Malamuthans tribal community. Totally 250 plants belonging to 86 families were reported to be present in the study area, in which Fabaceae family was the dominant one contributed 25 species followed by the families, Euphorbiaceae (16 species), Asteraceae (13 species) and Acanthaceae with 12 species and the distribution of species in the study area includes various life-forms viz., trees (81 species), shrubs (53 species), herbs (78 species), climbers (35 species) and epiphytics (3 species) habits respectively. Of the 250 plant species, 237 (95\%) were recognized as medicinally important and also cures 127 types of ailments. Of the 250 plant species encounted at all life-form levels. Sixteen ailment categories were classified, among them a higher number of 110 species were prescribed by the Malamuthan ethnic community for Gastro Intestinal Ailment (GIA).
\end{abstract}

Keywords: Ethnobotany, Malamuthan tribal, Medappara, Kerala.

\section{INTRODUCTION}

The indigenous people nurture rich knowledge about medicinal plants developed over generations by bold experimentation through trial and error methods (Sahai, 2003). This treasure of knowledge has been passed orally without any written documents and is still retained by them (Perumalsamy and Ignacimuthu, 2000). In the last few years, there has been an exponential growth in the field of herbal or traditional medicine and these drugs are gaining popularity because of their natural origin and exhibit remarkable efficacy in the treatment of various ailments (Siddhiqui et al., 1995). A vast knowledge of how to use the plants against different illness may be expected to have accumulated in areas where the use of plant is still of great importance (Diallo et al., 1999).

Ethnomedicinal studies are the suitable source of information regarding useful medicinal plants that can be targeted for domestication and management (Kunwar and Duwadee, 2003). These studies assume great importance in enhancing our traditional skills and technology about the plant grown and used for native or tribal communities for their sustenance. The use of ethnobotanical information in medicinal plant research has gained considerable attention in segment of the scientific community (Heinrich, 2000). Also, traditional medicine and ethnobotanical information play an important role in scientific research, particularly when the literature and field work data have been properly evaluated (Awadh et al., 2004). Many reports on ethnobotanical studies in the Nilgiri Biosphere Reserve of Western Ghats are available (Abraham, 1981; Parthasarathy, 1995; Rajan et al, 2003; Sivakumar and Murugesan, 2005; Pradheeps and Poyyamoli, 2013; Sharmila et al., 2014).

However no studies on ethnobotanical significances have been carried out in the Medappara Forest, Poovaranthode of Kerala, and a part of Nilgiri Biosphere Reserve where rich diversity of plant species is available. Hence the present study is aimed to document the medicinal plants of ethnobotanical importance in the study area of Medappara forest during the period between June, 2014 and February, 2015.

\section{MATERIALS AND METHODS}

\subsection{Study area}

The present study was made in Medappara Forest at Poovaranthode, Thamarassery Range which belongs to western parts of Nilgiri Biosphere Reserve, the Western Ghats, Kerala which spreads over an area of about 1400 hectares (Fig.1). It is a tropical moist evergreen forest consisting of multistoreyed structure encompasses high species content. The geographical location of the study forest is $11^{\circ} 23^{\prime} 45^{\prime \prime} \mathrm{N}$ and $76^{\circ} 06^{\prime} 18^{\prime \prime} \mathrm{E}$ and its altitude is ranging from $800 \mathrm{~m}$ to $2000 \mathrm{~m}$ above msl. 


\subsection{Ethnic community}

Malamuthans are one of the primitive tribal groups of Kerala living in Malappuram and Calicut districts including the study area, Medappara Forest. They are also known as Mala Namboothiris (tribal Brahmins) due to their strict beliefs and customs. The Malamuthan consider themselves as a very superior people and prefer to live isolated. They are fearless and loyal and clime to be the Malanamboothiris.

\subsection{Data Collection}

Ethnobotanical surveys were conducted during March, 2014 - February, 2015 in the Medappara forest of Kerala. The information was gathered through questionnaires, personal interviews and discussions among them (Schultes, 1962; Jain, 1989; Jain and Goel, 1995). The questionnaire contains the details of the plants, parts used, medicinal uses and mode of preparation of remedies. The taxonomic identification of the plant specimens were done with the help of local and regional floras viz., Flora of Presidency of Madras (Gamble and Ficsher, 1957) and Flora of Tamilnadu Carnatic (Mathew, 1983). The collected plant species were dried for herbarium preparation and the same were maintained in the Department of Botany, Kongunadu Arts and Science College, Coimbatore.

\subsection{Ailment Categories}

Based on the information obtained from the traditional healers in the study area, all the ailments were grouped into 15 categories viz., GastroIntestinal Ailments (GIA), Dermatological Infections/Diseases (DID), Respiratory Systems Diseases (RSD), Genito-Urinary Ailments (GUA), Fever (Fvr), Skeleto-Muscular System Disorders (SMSD), Poisonous Bites (PB), Circulatory System/Cardio-vascular Diseases (CSCD), Endocrinal Disorders (ED), Dental Care (DC), Hair Care (HC), Ear, Nose, Throat problems (ENT), Cooling Agents (CA), Liver Problems (LP), General Health (GH) and Insecticidal(IC).

\section{RESULTS}

\subsection{Documentation of indigenous ethnomedicinal knowledge}

The present study revealed the use of 237 species of plants distributed in 196 genera belonging to 86 families which were commonly used by most of the Malamuthan traditional healers for the treatment of 127 types of diseases. The prominent family of medicinal plants was Fabaceae with 25 species followed by Euphorbiaceae, Asteraceae and
Acanthaceae with 16, 13 and 12 species respectively. For each reported species, botanical name, family, parts used and ailments treated were provided (Table 1).

The medicinal uses of plants gathered in the present study were compared with the previously published information from various parts of India (Dasture, 1962; Pal and Jain, 1998; Maheswari, 2000; Sahoo et al., 2001; Suresh Babu, 2001; Shiva et al., 2002; Anilkumar, 2003; Kirtikar and Basu, 2005; Alice and Asha Sankar, 2007; Deshpande et al., 2010; Hrudayanath and Rout, 2011; Ayyanar and Ignacimuthu, 2011; Venkatachalapathi et al., 2015). The data showed that no plant was reported as a new medicinal plant as all the plants were reported with different uses elsewhere.

\subsection{Ailment Categories}

Based on the information obtained from the traditional healers in the study area, all the reported ailments were categorized into 16 categories (Table 2). Among the various ailment categories analyzed, higher number of 110 species was prescribed for a Gastro-Intestinal Ailments (GIA). Next to this, 86 plants were used for the treatment of Dermatological Infections or Diseases (DID) followed by 82 species for Skeleton- Muscular System Disorder (SMSD). For all other ailment category except insecticidal property, generally more than 5 species were used by the Malamuthan tribal communities in the study area, Medappara forest. However, for insecticidal properties (IC) only 2 species viz., Cycas circinalis and Duranta erecta were used. This data indicates the usefulness of various species for many ailment categories by the tribal community in the studyarea.

\subsection{Life-form and parts used}

The percentage of species distribution in various life-forms was varied markedly (Fig 2). Trees were the primary source of medicine (78 species) followed by herbs (71 species) and shrubs (52 species). Among the different plant parts used, the leaves (79 species) were most frequently used for the treatment purposes. Similarly, the root parts were also prescribed mainly (from 71 species) for many ailments. Very less number of species, less than 2 were used for their parts like corm, petiole, tuber, buds, twigs and grains.

\section{DISCUSSION}

Ethnobotany is perhaps the most important method to identify and study natural plant resources and their management by indigenous people. 
Table 1. List of plants with their families, parts used and uses included in major ailment categories.

\begin{tabular}{|c|c|c|c|c|c|}
\hline $\begin{array}{l}\text { Sl. } \\
\text { No. }\end{array}$ & Name of Species & Family & Parts used & Medicinal/other economic uses & $\begin{array}{l}{ }^{*} \text { Ailment } \\
\text { category }\end{array}$ \\
\hline 1 & Abrus precatorius, $\mathrm{L}$. & Fabaceae & $\begin{array}{l}\text { Roots, seeds, } \\
\text { leaves }\end{array}$ & $\begin{array}{l}\text { Roots, seeds and leaves are anti-phlogistic, aphrodisiac } \\
\text { and anti-ophthalmic properties. It is used as diuretic tonic } \\
\text { and emetic affections of nervous system and hair growth. }\end{array}$ & $\begin{array}{l}\text { ENT ,SMSD, } \\
\text { HC }\end{array}$ \\
\hline 2 & Acacia caesia,(L.) Willd. & Fabaceae & Bark, leaves & $\begin{array}{l}\text { The bark is used to produce a substance for washing hair, } \\
\text { which can be used to headlice.It can be also used to } \\
\text { stupefy fish. The flowers may be used ornamentally. } \\
\text { Tender leaves are used in the treatment of migraine. }\end{array}$ & HC, SMSD \\
\hline 3 & Acacia catechu (LF)Willd. & Fabaceae & Bark & $\begin{array}{l}\text { The liquid is very good for people suffering from obesity. } \\
\text { The extract of the plant is good for curing sore throat, } \\
\text { bronchitis and body pains. Bark used as an antipyretic as } \\
\text { well as anti-inflammatory substance. It cures psoriasis, } \\
\text { anaemia, ulcers, constipation and pain in the chest. }\end{array}$ & $\begin{array}{l}\text { GH, ENT, } \\
\text { RSD, DID, } \\
\text { GIA, }\end{array}$ \\
\hline 4 & Acacia concinna DC. & Fabaceae & Fruit, leaves & $\begin{array}{l}\text { The tree is food for the larvae of the butterfly. The "fruit } \\
\text { for hair" used as a traditional shampoo. An infusion of the } \\
\text { leaves has been used in anti- dandruff preparations. The } \\
\text { leaves have an acidic taste and are used in chutneys. }\end{array}$ & $\mathrm{HC}$ \\
\hline 5 & Achyranthes aspera L. & Amaranthaceae & $\begin{array}{l}\text { Whole plant, } \\
\text { leaves, root }\end{array}$ & $\begin{array}{l}\text { Decoction is used in fever and stomach diseases. Root ash } \\
\text { is used as tooth powder in pyorrhea. Used as } \\
\text { antispasmodic, astringent, Diuretic, odentalgic. }\end{array}$ & $\begin{array}{l}\text { GIA, } \\
\text { SMSD }\end{array}$ \\
\hline 6 & $\begin{array}{l}\text { Achyranthes prostrata,(L.) } \\
\text { Blume. }\end{array}$ & Amaranthaceae & $\begin{array}{l}\text { Roots, whole } \\
\text { plant }\end{array}$ & $\begin{array}{l}\text { Used by the Malays externally and internally. Decoction } \\
\text { used for coughs. Decoction of roots used for desentery. In } \\
\text { Cameroon plant used in prescriptions for articular } \\
\text { rheumatism. }\end{array}$ & $\begin{array}{l}\text { RSD, GIA, } \\
\text { SMSD }\end{array}$ \\
\hline 7 & Actinodaphne hookeri,Bedd. & Lauraceae & Rhizome & $\begin{array}{l}\text { The plant is used for aging, atherosclerosis, cancer, } \\
\text { diabetes, dysentery, mania, urinary disorders and wound. } \\
\text { Rhizome boiled is used for curing dandruff. The plant is } \\
\text { used in bronchitis and gynaecological disorders. }\end{array}$ & $\begin{array}{l}\text { GH, ED, GIA, } \\
\text { RSD, SMSD, } \\
\text { GUA }\end{array}$ \\
\hline 8 & Adhatoda zeylanica Medic. & Acanthaceae & Leaves & $\begin{array}{l}\text { Leaves are used against glandular tumors. The leaf extract } \\
\text { is used in the treatment of asthma for many centuries. It } \\
\text { relieves breathesnes }\end{array}$ & RSD, SMSD \\
\hline 9 & Adiantum philippense L. & Adiantaceae & Frond, root & $\begin{array}{l}\text { Fronds either in decoction or syrup utilized as Adiantum } \\
\text { capillus veneries. Roots used for strangury and for fever } \\
\text { due to elephantiasis. Used for cough, leprosy, hair falling. } \\
\text { Decoction of fresh leaves used as stomachic and diuretic; }\end{array}$ & $\begin{array}{l}\text { GUA, Fvr, } \\
\text { RSD, HC, } \\
\text { GIA, GH, ED }\end{array}$ \\
\hline
\end{tabular}


Asteraceae

Aglaia (Juss.)Benth

elaegnoidea

\section{Albizia falcataria (L.)Fosberg.}

Fabaceae

Albizia
(Osbeck.)Merr. chinensis $\quad$ Fabaceae

16

Albizia labbeck (L.)Benth.

17

Allmania

,(L.)R.Br.exwight in Hook

18

Alstonia venenata R.Br.

21

Fahaceae

Alpinia galanga (Linn.)Willd.
Amaranthaceae

Whole plant

Whole plant

Fruit

wood

Wood

Amaranthaceae

Zingiberaceae

Apocynaceae

Apocynaceae

Amaranthaceae

Rhizome

latex

Bark, fruit

Leaves
Leaves, seeds,

Fruits, root, bark, leaves

Bark, flower, Bark, flower and seed is used against cough, asthma, seed' leprosy and seminal weakness.

Ripe fruits, Ripe fruits are used in the treatment of constipation and leaves dysentery.Leaves; febrifuge

Rhizome is useful in rheumatism, bronchial catarrh, tonic,

Bark, milky

used as a cure for dysentery. Fronds extract used in fever, asthma and bronchitis.

Fruits are used in chronic dysentery conditions, accompanied by loose stools alternating with occasional constipation, the ripe fruit is widely used in differen Used as cooling agent and in diarrhoea. The leaves are used in the treatment of diabetes.

Used for treatment of snakebite. Leaves used for soup and spinach, plants included in Dasapushpam. The plant also used against cephalalgia and strangury.

Whole plant is used as a nervine tonic. Decoction or infusion of whole plant is used in diarrhoea, dysentery, colic with flatulence. Leaves are styptic, vulnerary and useful in haemorrhoids and sores.

Fruit is antidiarrhoeal, alternative, astringent, tonic,

employed in leprosy, burning sensation of the body, inflammations and febrile complaints; seeds used in painful matuaration.

feaves and seeds are used for eye problems. Wood is used for making paper pulp.

Wood is used for making furniture, packing box, tea box stomachic,carminative, stimulant expectorant, antispasmodic, anti-amphetamine and diuretic properties.

Bark and milky latex is used in the treatment of malarial fever, ulcer and helminthiasis.

The plant is used as snake antivenom by the tribals. Roots and fruits are useful for skin diseases, leprosy, cobra and other venomous bites, epilepsy, fatigue, fever, syphilis, insanity, helminthiasis as remedy for impure blood.

The plant is used against cough and diarrhoea in Brazilian
GIA, GH,CA

SMSD, GIA,

\section{ENT}

RSD,

SMSD,RSD, GIA.

Fvr, GIA

PB, DID, Fvr, CSCD, SMSD

GIA, DID, 
(L.)

\section{Amorphophallus hohenackeri}

,(shott)Engl.\&Gehrm.

\section{Andrographis}

(Burm.)Wall.

paniculata

Aristolochia indica ,L.

Artocarpus heterophyllus,

Lamk.

Artocarpus incisus (Thunb.) L.f;suppl.
Acanthaceae

Amaranthaceae

Whole plant

Araceae

Corm

Whole plant

Frond,

rhizome, stem

Leaves, fruits

Root, leaves

Aristolochiaceae Root, shoot

Moraceae

Moraceae popular medicine. Also used in inflammation. The leaves used in wounds.

The plant is bitter, sweet, astringent, acrid, constipating,

Roots, bark, Exude gum is used for boils. Roots are used for diarrhoea petiole, fruits and dysentery. Root bark is utilized in the treatment of exude gum depurative, digestive and useful in vitiated conditions of kapha and pitha, burning sensation, diarrhoea, leprosy and skin diseases.

Corm is used for the treatment of piles, prostatic hyperplasia. Corm is prescribed for bronchitis, asthma, dysentery, enlargement of spleen, elephantiasis etc.

The plant is used in the treatment of fevers, skin diseases, intestinal worms and flatulence. The decoction of plant is administered against chronic fevers, intestinal worms and dyspepsia.

The stem and rhizome are used in treatment of

indigestion and other bowels related problems of cattle and goats. The portion of bark is given orally to cattle in dysentery occurring during rainy seasons.

Leaves are considered as an antidote to the sting of cobra. Fruits are edible.

The roots are used to treat malaria, typhus fever, small pox and pneumonia. Poultice of roots are used on open wounds and skin ulcers. Leaves used as antidote for poisonous stings and also to treat skin diseases.

The root is used for the treatment of snake bite. Shoot extract is used for abdominal pain.

Latex applied externally on burns. Fruits are edible, sweet taste used in treatment of cancer. Wall of the young fruit is removed and the inner portion is cooked in goat milk and eaten for ulcers. Juice applied externally to glandular swelling and abscesses to promote suppuration.

$\mathrm{GH}, \quad \mathrm{RSD}$, GIA, DID

GH, RSD, fractures.Petiole used for eyesores and irritation. Fruits are edible. 

(J.Jacq.) Nees

\section{Bidens pilosa, L.}

Biophytum sensitivum, DC.

Bixa orellana Linn
Euphorbiaceae

Euphorbiaceae

Begoniaceae

Acanthaceae

Asteraceae

Oxalidaceae

Bixaceae

The roots are bitter, sweet, emollient, cooling, nervine tonic, constipating, ophthalmic and tonic. They are useful

tumours, burning sensation, inflammations and ENT ophthalmopathy.

Whole plant

Leaves

Flower, stem

fruit

Fruits

Root

Leaves, buds,

root

Leaves

Leaves, root, stem

Whole plant

Whole plant

Fruit, seed, root bark
Juice of the plant administered to children suffering from swellings, worms and rheumatism.

Fresh leaves are used against honey bee sting.

Flowers and stems are good source of iron, vitamin B and C. Fruit is astringent, stomachai and cooling; in the form of GIA, CA, GH, curry useful in piles and scurvy.

The fruits are acidic in taste and are edible.

Root is used in the treatment of dropsy, constipation, anaemia.

Tender leaves or buds decoction are used to relieve menstrual irregularities. Decoction of tender buds used for leucorrhoea, fever in children and diarrhoea. Natural cure for bronchial ailments for asthma. The dried roots are powdered and prepared into paste with water and externally applied over scabies.

Leaves used for treatment of respiratory infections, diarrhoea, blood cancer and skin diseases. Very few reports on cultivation.

Snake grass use initial treating snake bites. It is used for cancer. The leaves, root, stem of vishapacha is used kapha, pitha, poison bites and swelling due to viper bite.

eaf paste is applied on cuts and wounds.

Plant juice is applied on the injured part and also for

bleeding. Plant paste is applied on forehead for migraine. Fruit used as an astringent, purgative. Root bark- antiper, antipyr. Seeds cordial good remedy for gonorrhea. Leaves used in jaundice and snake bite. Seed pulp used for making dye called "Arnotto" once largely used in dyeing silk and cotton.
CA, SMSD

SMSD, GIA

GUA, Fvr,

GIA, RSD

RSD, SMSD DID, $\mathrm{PB}$

SMSD, RSD, $\mathrm{PB}$ 
Whole plant

Breynia retusa (Dennst.) Alston,Ann.

Clusiaceae

\section{Carallia}

(Lour.)Merr.

\section{brachiata}

Rhizophoraceae stem

Leaf, seed fruit
The plant is used in traditional Chinese medicine. It is also used as decorative dry plant. The plant have pungent, bitter and antipyretic properties

Bark is used in diseases of nervous system, oedema,

disorders of blood and conjuctivities. Leaves are employed as poultice to hasten suppuration and as a galactagogue.

Bark is used in the treatment of rheumatism.

Leaves used as astringent, antiseptic and counterirritant against poisonous insect bites. Pounded fresh material is applied as a poultice for a variety of conditions: sprains, eczema, infections. Leaves used for asthma and headache. The plant is used as a fresh dietary vegetable.

The cane is used for reinforcement of walls, making basket. Barks are used to extract tannin and also for ayurvedic medicinal purposes.

Used in Ayurvedic system of medicine for curing cough and oedema.

Decoction of root used as a protective medicine after child birth. The leaves applied hot are reported to give Root, leaves, relief in rheumatic pains. Preparation of flowers are used flowers as a diuretic for diseases and ailments of the kidneys and the lower urinary tract.

The stem bark is evaluated for wound healing activity used in treatment of cuts and wounds. The wood is

Stem bark, suitable for general construction, house building, posts, cabinet work, railway sleepers, furniture, musical instrument etc.

Wood , bark, Wood useful; bark and fruits astringent flowers and bark fruits, flowers, used in the treatment of cough and cold; fruits edible. Stem used for tooth cleaning.

The plant is used in hyperdypsia, fatigue and hemicarnia. Leaf bud, seed and toddy are used for diarrhoea, migraine and scorpion- sting poisoning.

Bark, root, Bark, root and fruit is used in the treatment of syphilis, 


\section{Centratherum intermedium}

Asteraceae

Leaves

$58 \quad$ Chassalia Chassalia curviflora
(Wall.exKurz) Thw.

Rubiaceae

Root Chromolaen

Asteraceae

Cinnamomum malabatrum

(Burm.f.) Blume.

Cissus latifolia, Lam.

Citrullus colocynthis (L.)

Cleome burmannii, wight \&Arn.

plant

Whole plant
The plant extract is used in the preparation of hair oils and tonics. It is also used as a vegetable. Leaf paste used for scorpion sting. Whole plant used in the treatment of cardiac debility, abdominal disorders, epilepsy and leprosy.

The perennials are best planted in groups suited for rockeries, as well as ground cover.

The plants extensive root system makes it useful for stabilizing soils and controlling erosion. Make a poultice from the leaves with a pinch of salt and use to reduce swelling.

Root decoction used for cough and malaria. It is also used as an adulterant for " sarpagandha".

Leaf juice is applied externally on cuts and wounds to stop bleeding.

The wood is used for making furniture. The plant have anti-inflammatory properties. The leaves used to making traditional food.

Whole plant cooked with jaggery is used for burning fever and pleuritics. Water dripped from the trunk with sugar is useful for cough, purifies blood, cure the ulcer of lungs. Crushed root boild in water is good toothache.

Fruits are given in low doses in cases of urticarial, constipation and toxemia.

The leaves and seeds are used as a rubefacient and vesicant by traditional medicinal practitioners in Africa and Asia. They are also used to treat infections, fever, rheumatism and headache.

Bark is used for diabetes. Leaves are used as bitter tonic, vermifuge, laxative and cholagogue; fresh leaf juice used GIA, to remove ascarids,leprosy.

Crushed leaves are used in the treatment of dysentery.

Roots contains an antidote for certain snake bites. A paste GIA, PB of the leaves applied to infected burns.
$\mathrm{HC}, \quad \mathrm{PB}$ CSCD, SMSD

SMSD

RSD, Fvr

RSD, CSCD,

Fvr, SMSD, 
rassocephalum

crepidiodes,(Benth.)S.Moore. Asteraceae

\section{Crotalaria}

pallida

(Dryand.)Ait.

\section{Crotalaria verrucosa $\mathrm{L}$.}

Cuphea hyssopifolia, Kunth in HBK, Nov.Gen.

\section{Curculigo orchioides Gaertn.} Cyathia gigantia,(Wall.ex Hook)Hottum.

Cycas circinalis Linn.

Cyclea peltata (Lam.) Hook.
Fabaceae

Fabaceae

Lythraceae

Hypoxidaceae

Cyathiaceae

Cycadaceae
Leaves, stem

Root, leaf,

seed

Whole plant

\section{Whole plant}

Rhizome

Roots, leaves

Root,

seed

Whole plant

Root stalk

Whole plant

Male cones,

bark

Tuber
Root, leaf and seed are used against leucoderma, pulmonary tuberculosis and otalgia.

Whole plant is taken orally along with water three times a day for a period of two days to get relief from burning micturition.

Whole plant is used for haemorrhage, leprosy and

rheumatism.

SMSD

Rhizomes are aromatic and used for haemorrhage, fever, cough, and other respiratory diseases, diabetes, blood diseases, leprosy and other skin diseases.

Fvr, RSD, ED CSCD, DID

Its fleshy mucilaginous leaves and stems are eaten as a vegetable. A lotion of leaves is used as a mild medicine that strengthens the stomach and excites its action. Leaves used in treatment of wounds, headache.

Roots and leaves are used for diarrhoea, dysentery, bleeding disorders, swelling, leprosy and other skin diseases.

GIA, DID

SMSD

GIA, SMSD

DID

GIA, SMSD, emetic, swellings, leprosy and other skin diseases.

Oils and serums derived from the plant often used in prevention of organ stones. Subsidence of consumption and fever, curing of infection especially with eyes.

It is used in piles. It also used in the treatment of leucorrhoea, asthma, hydrophobia. The root poultice is applied for itching sensation and rashes.

The plant useful in continuous fever. Gum is used as a binder and disintegrater in tablets.

Male cone marketed and used to prevent the entry of mosquitoes and other insects in to houses /dwellings including cowsheds. Children are given bath in water soaked with bark and peeling to prevent skin diseases. Tuber is used for dysentery.

\section{Fvr, ENT}

GH, RSD, DID

Fvr

IC, DID 
\&Thoms

78 Cyperus cyperinus,(Retz.) Sur.

79

Cyperus haspan, L.

80

Dalbergia latifolia Roxb.

81

Debregeasia

(Burm.f.)Wedd.

longifolia

Dendrocalamus

(Munro)Kurz.

brandisii

Desmodium triquetrum (L.)
DC.

Desmodium gangeticum (L.)
DC.

85

Desmodium heterocarpon,

(L.) DC.

terocarpon,

motorium

Desmodium

(Houtt.)Merr.

Dimocarpus longan Lour.

Diospyros paniculata Dalz.

Ebenaceae
Fabaceae

Fabaceae

Fabaceae

Fruits

Fronds,

rhizomes

Cyperaceae

Fabaceae

Sapindaceae

Fruit

Euphorbiaceae Leaf, fruit

bark,root
Astringent, appetiser, stomachic, anthelmintic, leprosy,

thirst, fever and used for the treatment of blood diseases.

The plant is used for making baskets and mats.

Paste of the stem bark is internally given for diarrhoea

Leaf, stem .Decoction of the bark is given in dyspepsia and obesity.

Two-three drops of leaf juice are poured in to the ear to get relief from ear pain. Root paste applied on forehead to reduce headache.

Stem, wood, Stem fibre is used for ropes and cordage. The wood is used for making charcoal. Fruits are edible.

Used as a raw material in paper mills. Leaves are used as

forage, and decoction of the leaves, nodes and silicious matter is used in traditional medicine.

Extract of herb used in piles.

Root is used for the treatment of fever, asthma and dysentery.

Fvr, RSD, GIA

The boiled roots are used in Malaysia to poultice sore breasts, and a decoction of the plant is regarded as a tonic and bechic. In Taiwan a decoction of root is used against rickets in children.

A herbal antidote. The decoction prepared by whole plant medicinally used as an antidote.

The fruit is used in promoting blood metabolism, soothing nerves and relieving insomnia. Pericarp have antiinflammatory property.

Dried and powdered fruits are applied to heal burns. A decoction of the fruit is used in gonorrhea, biliousness and blood poisoning.

Fronds used for poulticing swellings. Rhizomes astringent, aqueous extract possesses antibacterial properties.

SMSD,

Leaf and fruit are used in the treatment of cold and fever. RSD, Fvr

GIA, Fvr,

GIA, $\quad$ GH,

ENT, SMSD

$\mathrm{GH}$

$\mathrm{GH}$

GUA, SMSD

PB

CSCD, SMSD,

GH, DID,

PB, GUA 


\section{Elaeocarpus tuberculatus} Roxb.

\section{Elephantopus scaber, L.}

Eletteria cardamomum, Maton.

Zingiberaceae

Myrsinaceae (Muell.Arg.) Croizat.

Fabaceae

Rutaceae
Euodia lunu-ankeda Merr.

Euphorbia hirta, L.
Euphorbiaceae flower fruits, root

Leaves root
Macerated fruits yield a juice diluted in water can be used Root, leaves, calculi, leprosy, retention of urine, bronchitis, skin Root bark, fungal infection, indigestion and headache. Leaves useful Wood, leaves, Wood is used in match industries. Root have immune
modulatory activity. Aromatic leaves used in cooking. Leaves, latex, keep the eye cool. The root is given to allay vomiting. root as a larvicide in ponds and swamps for killing mosquitos.

It is good for hair and skin, expels intestinal worms, cures cough and asthma. It is specific in night blindness, eye diseases and headache.

The fruits are appetizer and sedative and are useful in cough. Wood used for planking. Decoction of the bark used in haemetemesis, indigestion and biliousness. Nuts used as remedy for rheumatism, typhoid fever and epilepsy.

Whole plant is used for diarrhoea, hemorrhage, urinary disease, intermittent fever, hepatopathy, ophthalmopathy, cough and swellings.

The dried capsule is chewed for pleasant aroma and pungent taste.

Root bark is acrid, astringent, anthelminthic, antifertility, digestive, stomachic and laxative. It is used in treating intestinal parasites and worms, abdominal disorders, skin in leprosy. Fruits laxative useful in nervous debility, dyspepsia, tumors and asthma. The root decoction used for heart diseases.

The plant is used against dysentery. The decoction of leaves used as febrifuge.

The plant is used to treat digestive problems and dysentery.

The paste of the leaves is applied on the wounds of the cattle for healing. Plant traditionally used for menstrual cramp.

Latex is used in eye trouble and plant paste is applied to

IC

HC, DID,GIA, RSD, ENT, SMSD

GIA, RSD SMSD, Fvr

GIA, ED, RSD, DID, Fvr ENT, SMSD

Leaves are used as antidote to snakebite and scorpion ENT, PB 
Moraceae

Ficus racemosa L.

Moraceae

Moraceae

Ficus tictoria G. Forst.

jungomas

108

\section{Flacourtia}

(Lour.)Raeusch.

109

Flemingia macrophylla (Willd.)

Prain ex Merr.

110

Garcinia

Roxb.

gummi-gutta

(L.)

Clusiaceae
Glycosmis
(Retz.)DC.

pentaphylla,
Fruit, root

Latex

Aerial root, Bark, latex

Wood

Bark, fruits

Bark, fruit

Root bark

Leaves, fruits

Roots

Seeds, tubers

Whole plant
The milky latex used as purgative rubefacient and expectorant to remove warts and cutaneous eruptions. The latex is drastic purgative used to treat obstinate constipation.

Milky latex applied externally for pains in rheumatism and lumbago. Aerial root is used against leucorrhoea, haemorrhages and bruises.

The fine wood is usually used for furniture.

Bark and fruits are used for ulcers, leucoderma, psoriasis, anaemia, jaundice, epistaxis and inflammations.

Milky juice is used in piles and diarrhoea. Decoction of the bark is administered orally to cure dysentery. The fruit is given as a tonic for pregnant women.

The root bark is stomachic and aperient

Dried leaves are used to treat asthma. The fruits and leaves are used against diarrhoea,. Dried leaves used for bronchitis. Also used in treatment of dyspepsia and diabetes.

Roots used for ulcers and swellings.

Fruits are used for the treatment of dysentery. Milky juice contain arabin, essential oil, resin used in treatment of rheumatism and bowel complaints. Root used quire the swelling the body due to viper bite. Plant used in food preparation and preservation. Extract used in traditional medicine as purgative. Kudampuli (dry fruit) helps to promote digestion and a decoction used against arthritis. It is used against rheumatism. Plant used in the treatment of infertility, open wounds, snakebite, ulcers, arthritis, cholera, colic, kidney problems, typhus, itching and cancer. Rhizome used in the treatment of ulcer, leprosy and expulsion of placenta.

The plant is used as herbal remedy for various ailments. It is used to reduce blood glucose. Leaf fresh juice orally for

GH, DID

SMSD, GUA

RSD, GIA, ED

GIA, SMSD,

liver conditions. 
Heliotropium indicum, L. Ham)Wall.

Hoya sp.

Hypoestes
Boraginaceae

Hemidesmus indicus (L.) R.Br. Asclepiadaceae

Hemigraphis colorata Hallier f. Acanthaceae

Hibiscus hispdissimus Griffith.

Holarrhena pubescens (Buch.-

Holigarna arnottiana Hook.f.

Hook.

sanguinolenta

flowers

stem

Root, leaf, Root, leaf and fruit is used against hallucination, piles,

Root, bark, diabetes and diarrhoea. The bark used against dysentery. fruit Fruit demulcent, astringent and used in griping and

Leaves,

Root, leaf, burning sensation, leucoderma, leprosy, skin diseases,

Malvaceae

Anacardiaceae

Bark

Leaves, whole plant

Leaves, roots

\section{Apocynaceae Bark, leaf}

Dipterocarpaceae Wood, resin

Asclepediaceae Leaves

Acanthaceae
Whole plant ulcer, growth of hair and anaemia.

Root, bark and fruit is used in the treatment of scabies, flatulence of bowels and other abdominal complaints.

The plant is emollient and diuretic used as local

application for ulcers, wounds. Decoction of leaves used in urticaria and fevers. Flowers considered emmenagogue in small doses and abortifacient in large doses.

The roots are bitter, sweet,astringent. They are useful in

bronchitis, syphilis and rheumatism. The leaves are useful in vomiting, wounds and leucoderma. Stems are laxative useful in inflammations.

In Kerala leaf juice is applied on wounds. In Indonesia the plant is astringent, antidiarrhoeal used in the treatment of

GH, GIA, HC

GIA, DID, Fvr, GUA

DID, RSD

SMSD diarrhoea, dysentery, kidney stones, dermatoses and wounds. The leaves are used in the treatment of oliguria, haemorrhoids and post- partum bleeding.

Leaves are anthelmintic and improves digestion. Infusion of roots are considered to be useful in inflammations, helminthiasis, dyspepsia and ophthalmopathy.

Used in the treatment of amoebic dysentery, asthma, malaria and chronic bronchitis.

In Ayurveda, the plant is used in treatment of

inflammation, arthritis, hemorrhoids, obesity, tumour, cancer and skin diseases. The dried bark of the plant is used to cure amoebic dysentery. It is febrifugal, stomachic. Wood brown, close-grained, hard, used extensively in house construction for planking, as piles for bridges, for making platform boards, agricultural implements for making railway sleepers and electric poles. The resin used as a medicine applied to sores and wounds.

Used as a treatment for asthma. The plant is used in treatment of headache, diarrhoea and SMSD, GIA, wounds. The plant also used to making bonsai.
DID, GIA, LP,

GIA, DID,

ENT

GIA, RSD

Fvr

DID, SMSD, GH, GIA 
Hyptis suaveolens, (L.) Poit.

Lamiaceae

Leaves

Ichnocarpus frutescens (Linn.) Anocvnaceae R.Br.

Impatiens balsamina, L.

Impatiens cuspidata (Wight Impatiens hensloviana Arn.

Balsaminaceae Impatiens minor, (DC.)Bennet. Impatiens scapiflora, Heyne ex Roxb.

Ipomoea hederifolia, L.

Ipomoea mauritiana Jacq.

Convolvulaceae

Leaves, root

Ipomoea nil, (L.) Roth.

Convolvulaceae

Seeds, leaves

Ipomoea obscura, L.

Convolvulaceae

Rubiaceae

Acanthaceae

Justicia gendarussa Burm.f.

Justicia japonica,Thunb.

Knema

Hook.t.\&Thoms.)Warb.

Whole plant

Whole plant

Whole plant flnisare shoots

Whole plant
The plant is stimulant, carminative and lactagogue. Infusion used in catarrhal conditions, uterus affections and parasitical cutaneous diseases. Leaf juice given in colic.

Root is used for treatment of fever, seminal weakness and diabetes.

Plant is useful in amenorrhoea, dysphagia, eye disorders

as sores and redness, urinary, rheumatism and vomiting. Juice of leaves and branches is effective against burns, also for snakebite.

The plant is used for treatment of skin diseases.

The plant is used for treatment of blood related diseases.

The plant is used as an ornamental and cosmetics.

In North America the plant have been used as herbal

remedies for the treatment of bee stings, insect bites and stinging nettle rashes.

Leaf juice is applied for cuts and wounds.

The leaves and roots are used externally to treat

tuberculosis and for the treatment of external and breast infections. The decoction of the tuberous roots are used for the preparation of medicinal wine.

Seed is acrid, light, anthelmintic, purgative and blood purifier. It cures inflammations, abdominal diseases. Juice of leaves used for fever, headache and bronchitis.

Fvr, ED

ENT, ED

SMSD, PB,

GUA

DID

CSCD

DID

PB

The leaves have a pleasant smell and mucilaginous taste, used as valuable application in aphthous affection. Leaves used for eye diseases.

Roots, leaves and flowers used as a blood purifier,

Roots, leaves, antiseptic, infantile skin ailments, diarrhoea, dysentery, fever, sores, chronic ulcers and catarrhal bronchitis.

Leaves, tender

In the form of decoction it is given in chronic rheumatism.

Plant extract is used as antiperiodic.

CSCD, Fvr SMSD, RSD

\section{ENT}

CSCD, DID

GIA, Fvr,

ENT, RSD

SMSD

Fvr

Medicated ghee is used for treatment of spleen disorders, breathing disorders and tastelessness. 
Kyllinga nemoralis, (J.R \& \&Dalz.

Root

Lantana camara L.

Verbenaceae

Whole plant

142

Leea

143

Lepianthes

(L.)Rafin.

144

Leucas aspera Spr.

sambucina

umbellata

Leeaceae

Piperaceae

Lamiaceae

Scrophulariaceae Whole plant

Lindernia viscosa, (Hornem.)

146

147

$$
\text { Kern. }
$$

Lobelia nicotianifolia, Roth ex

Roem.\&Schult.

Ludwigia

octovalvis,

(Jacq.)Raven.

Lygodium flexosum (L.) SW.

Lygodiaceae

Root

Macranga indica Wight.

151
Euphorbiaceae

Leaves, fruits

Euphorbiaceae Fruits
The plant widely used throughout the world and frequently used for its anti-venom property. It is having analgesic, antidiabetic, anticancer, hepatoprotective, antioxidant and antimalarial properties.The tubers are astringent and febrifuge.

Root is stimulant and used in the treatment of fever.

Fvr

Leaves is used for haemorrhage, disease of kapha and diarrhoea. Decoction of whole plant is given in tetanus, rheumatism, malaria and for ataxy of abdominal viscera.

Leaves and twigs have antiseptic properties and are used for poulticing. Root thirst reliever, cooling properties.

Leaves are used for poulticing.

ED, GIA, DID

Fvr,

RSD, GIA, PB, SMSD, Fvr

DID, CA

The leaf paste is applied on forehead for the relief of

headache. The leaf decoction is used in the treatment of SMSD, DID, scabies. The root decoction is used for the treatment of PB snakebite, also used as an antidote to poison.

The plant is used in traditional medicine.

The plant is used for ornamental purposes.

It is used to treat asthma and bronchitis. It causes irritation of mucous membrane, toxic.

RSD

Whole plant is useful in dyspepsia, verminosis, flatulence, strangury,dropsy,cough,asthma and neuropathy.

GIA,

$\mathrm{RSD}$

Used as an expectorant. Fresh roots used in external applications for rheumatism, sprains, scabies, eczema and wounds.

Different parts of the plant are used quite frequently in various traditional medicines. Sometimes a gum exuded from the cut branches, petiole bases, young shoots and fruits of the plant are applied externally to get relief from venereal sores. Leaves used in bronchial troubles and consumption.

Glandular hair from fruits yield a reddish powder used as
SMSD

RSD, SMSD,

DID

GUA, RSD

GIA 
Muell.Arg.

Mastixia arborea (Wt.)Bedd. Cornaceae

\section{Michelia champaca Linn.}

Miconia calvescens DC Microsorum nigrescens Blume) Copel.

Microstachys chamaelea, (L.)

Muell. Arg.

\section{Mikania micrantha, Kunth in} HBK, Nov. Gen.

\section{Mimosa diplotrica,C. Wight.}

Melastomataceae

Bark, leaves

Meliaceae

Leaf

Convolvulaceae

Whole plant

Root, flower,

leaves oil

Wood, flower,

bark, fruit

Melastomataceae Wood

Polypodiaceae

Fronds

Euphorbiaceae

Asteraceae

Whole plant

Mimosaceae

Whole plant

Mimosaceae an anthelmintic and useful in cutaneous affections. It is also used against tapeworms, abdominal disorders, haemopathy andleprosy.

The plant is used against uterus diseases. Fruits green to be taken as stomach medicine. Small - sized timber used for fuel wood.

Bark and leaves are used in diarrhoea, dysentery, mucous discharge, piles and haemorrhages.

Leaf paste mixed with rice water taken cures dysentery.

Whole plant is used for urethral discharges. Roots are eaten by tribals as a stomachic.

Root bark is astringent and aromatic used in rheumatism. Leaves are used as poultice for pustular eruptions. Flowers are used in cough attended with expectoration.

The wood is used as fire wood.The flower is used for the treatment of kapha, pitta. Bark, flower and fruit used in the treatment of amenorrhoea, gastritis and cough.

The plant used for construction or stuck on wheels of bulldozers.

Used against nasal infections, extract is used as a source of medicinal agents to cure urinary tract infections.

Decoction given with ghee as atonic; also applied in vertigo. Juice used in diarrhoea.

It is used to heal cuts and stop minor external bleeding. Used as a local antiseptic medicine.

In Indonesia, the plant is used as a fodder to buffaloes. It is used as a garden flower.It is used as a herbal medicine Root decoction is used in gravel and urinary complaints. Juice of leaves used in dressings for sinus and also for ED, GH, GIA, sores and piles. Whole plant is haemostatic and is used in GUA, DID diarrhoea, uterine disorders and skin diseases. 

Mitracarpus verticillatus (Schum. \&Thonn.)Vatke

\section{Whole plant}

Root

Morinda citrifolia L.

Rubiaceae

Fabaceae

Mucuna pruriens (L.)DC.

Commelinaceae

Root,

seed

$$
\text { leaf, }
$$

Whole plant

Rubiaceae

\section{Whole plant}

Myristicaceae

Dried

fruits,seeds

Mytragyna parvifolia

Myxopyrum Blume. spilacifolium

Rubiaceae

Oleaceae

Meliaceae

\section{Naregamia alata W. \& A.} Naringi
Nicolson. Rutaceae Ochlandra scriptoria, (Dennst.)Fischer.

Poaceae

Root, bark

Stem, oil

Whole plant bark, leaf
Lamiaceae

Ocimum basilicum, L.
Bark is used treat diarrhoea and dysentery. A decoction of bark is used as gargle. The fruit and bark possess tonic and astringent properties.

Extract useful in cosmetics for lightening skin, removing brown patches.

Root used for making dye. "Al-Dye" red, purple, chocolate shades are produced on mordant cotton, silk or wool. The plant have an anti-inflammatory and anti-oxidative property.

Root, leaf and seed is used against dropsy, helminthiasis and sterility.

It is used as fodder for animals.

The plant is astringent, useful in bronchitis, cough, fever inflammation, jaundice, leucoderma. Leaves are useful in inflammation, to expel intestinal worms, ulcers and on swellings and headache.

It is used in Ayurvedic medicine. And has been shown to have anti-cancer and anti-inflammatory properties.

The roots and bark are acrid, bitter, stomachic and

febrifuge. A decoction of the root is taken to relieve GIA, RSD, asthma and diorrhoea. The plant is used in menorrhagia, piles, minor skin wounds, fistula and diabetes.

Oil is used as a medicine to migraine in siddha medicines. Stem also used as a medicine for migraine.

Used for the treatment of rat poison and doing naseum in

snake treatment. Also used for rheumatism and inflammations.

Root, stem, Exhibited significant antitumour activity .Root is used as remedy for cobrabite, vomiting and desentery. Bark is used as a remedy for puerperal fever and pitta.

SMSD, GIA

$-$

RSD, Fvr DID, LP, GIA, SMSD

SMSD, DID

GH, DID, ED

SMSD

PB, SMSD,

DID

SMSD, PB, GIA, Fvr RSD

Thin, tough and pliable strips of immature culms are used to make textiles, mats and screens, lashings etc. Stem used to make flute.

Whole plant is used for cough, asthma, bronchitis, ophthalmia, giddiness, intermittent and malarial fever, catarrh, otalgia, cephalalgia, dyspepsia and spasmodic affections.
Leaves, seed 


\section{Panjanelia longifolia (Willd.) \\ K.Schum.}

Parahemionitis

cordata

,(Roxb.Ex Hook.\&Grev.) Fraser

Paspalum scrobiculatum, L.

Persea macrantha (Nees)
Kosterm.

\section{Persicaria chinensis}

(L.)
Rhizomes

Rubiaceae

Oleaceae

Rubiaceae

Whole plant

ignoniaceae

Bark

\section{Melastomataceae Whole plant}

Bignoniaceae Whole plant

Pteridaceae

Poaceae

H.Gross

Phyllanthus

amarus,

187

\section{Phyllanthus emblica L.}

\section{Schum.\&Thonn.}

Ephorbiaceae

Euphorbiaceae

Pilea micropylla,(L.)Liebm.

\section{Lauraceae}

Polygonaceae

Whole plant

Bark,

bark, leaves,

fruits

Leaves
The rhizomes are stomachic, carminative, stimulant and tonic and are used in dyspepsia in the form of powder and decoction.

Bark and leaves used as a febrifuge and emetic.

$\mathrm{FVr}$

Whole plant is useful in wounds, ulcers, helminthiasis, snake poison, hydrophobia, cancer, gastropathy and leprosy.

Decoction of bark is given in toxemia, rheumatism and cancer.

The plant traditionally to treat liver diseases. Aqueous extract should immunomodulatory effects in Taiwan, a decoction of the aerial part is used as a drink to treat dysentery.

The plant is employed in Malaya medicinally for same purposes a "Syonaka".Nervine tonic.

Extract used as a source of medicinal agents to cure urinary tract infections. The rabbits ear fern used in the treatment of earaches and as a vermifuge.

The grains are sweet, bitter astringent useful in ulcers,

flatulence, diarrhoea, hepatopathy, haemorrhages and general debility.

The plant used for the treatment of asthma and

rheumatism. The stem bark used as anti- inflammatory and anti- arthritic.

Whole plant is used as a tonic, anti-scorbutic and vulnerary.

Plant is used in jaundice, flue, dropsy, diabetes, asthma, bronchial infections, and diseases of liver .In Ayurveda used in problems of stomach, liver and kidney.

, GIA, PB SMSD

SMSD, CSCD

ED, ENT, GIA

RSD,

LP, Fvr, ED,

The root bark is useful in ulcerative stomatitis. Bark is used in gonorrhea and jaundice. Leaves effective for GIA, LP, diarrhoea. Fruits are used for cardiac diseases and CSCD, tuberculosis.

The plant is used in gastric and intestinal troubles. Infusion is given as a diuretic. Crushed leaves are applied to bruises. 
190

Piper longum, L.

191

Plumbago rosea, L.

192

Dalz.
Piperaceae

Fruit

Plumbago zeylanica L.

Plumbaginaceae

Root

Pogostemon purpurascens,

Pongamia pinnata (L.) Prierre.

Fabaceae

Araceae

Pouzolzia indica,(L.)Bennett.

Urticaceae

Verbenaceae

Leaves, roots

Bark, lea

flower, oil

Root, stem,

leaves

Roots

Premna tomentosa, Willd.

Pteris confusa,T.G.Walker.

Pteridaceae

Spores

Heart wood leaf, flower

Fabaceae
Fruit used in the treatment of cold and cough. Used to treatment of heart burns, indigestion and diarrhoea.

RSD, CSCD

The root and root bark is bitter and dry with stomachic,

carminative astringent and anthelmintic used in gastro intestinal diseases, dysentery, diorrhoea and dyspepsia. This tincture is also used for the treatment of haemorrhoids.

Root is used in the treatment of rheumatism, diarrhoea and piles.

Leaves are styptic and used to clean wounds and for promoting granulation. Roots are used in uterine haemorrhage, snake bite and scorpion strings. Leaf juice is given in fever.

Bark, leaf, flower and oil is used in the treatment of

beriberi, diabetes, scabies and leprosy.

Root bruished and fried in oil for application to abscess. Stem cut smoked with camphor for relief in asthma. Powdered leaves are applied to smallpox pustules.

Roots mixed with Badra used in gastric problems, sores, boils, ulcers, de-worming and galactagogue.

Used to treat stomach and liver disorders. The leaves are used in treatment of cough, headache and fever. The leaves and roots are used as a diuretic, stomachic and febrifuge.

Guava seed oil used for culinary uses, pharmaceuticals or cosmetics. In cosmetic industry, the oil is used in skin care

Fruit, seed, products. A tea made from young leaves useful for

leaves, bark diarrhoea, dysentery and fever. Fruits are edible. The entire fruit is key ingredients in punch, and the juice often used in culinary sauces, dried snacks. Bark used for tanning and dyeing purpose.

The fern spores are used to screen the hyper accumulating ferns
GIA

GIA, GH

SMSD, GIA $\mathrm{GH}$

DID, GUA PB, Fvr

ED, DID

RSD,

LP, RSD SMSD, Fvr GIA

DID, GIA, Fvr

SMSD RSD, Fvr
Heart wood, leaf and flower are used in the treatment of fracture, rheumatoid arthritis, asthma, boils and fever. 


\section{Rhaphidophora}

pertusa,

(Roxb.)Schott.

Araceae

Ricinus communis Linn.

Euphorbiaceae

Rosa multiflora, Thunb.

Rosaceae

Simaroubaceae

Scoparia dulcis, L.

211 Selaginella (Sw.)Spring involvens,

Selaginellaceae
Aerial part,

stem

Leaves, seeds,

roots, oil, fruit

Leaves, fruit

Whole plant

Roots

Root

Seed, leaves, oil

Bark, flower,

seed

Whole plant

Whole plant
The herb is effective in treating insomnia. It is very useful in lowering the B.P. Used for the treatment of hypertension and nervousness. Root is also used for the treatment of epilepsy and snakebite.

Whole plant is used in snake bite and scorpion sting. Stem used in ulcers, pain in the colon, bronchitis and very specific for abdominal tumour.

Castor oil used on the skin to prevent dryness. The plant is harmless purgative and very effective in treating

rheumatic and skin disorders.

The leaves are poulticed and applied to sores. The fruit is

diuretic, antidotal to fish poisoning, hypoglycaemic and laxative. It is used to treat constipation and articular pain and as an application to foul ulcers.

It is used as ornamental for acquaria.

Root is used in asthma, bronchitis, abdominal disorders, epilepsy, indigestion, respiratory diseases, burning sensation and intermittent fever.

Roots are used for treatment of diabetes, bleeding piles, gonorrhea, inflammations, leucorrhoea, leprosy, skin diseases, wounds, ulcers, indigestion, flatulence, colic and spermatorrhoea.

Seed is emetic, purgative; used for bilious fevers. Seed oil applied in rheumatism. Leaves are used as a gargle in sore throat.

Bark, flower and seeds are used against dyspepsia, colic, menorrhagia, hyperdipsia and bone fracture.

The entire plant including the roots, possesses antiinflammatory, anti-fertile and anti-diuretic properties. It is used in treating coryza, hyperthermia and sore throat.

The plant is used to treat cirrhosis. It have antimicrobial property. Non-antibiotic source in therapeutic application of the treatment of acne development by reducing the chance of non -specific initiation and augmentation phase of the inflammatory response.
$\mathrm{GH}, \quad \mathrm{CSCD}$ SMSD, PB

PB, GIA, RSD SMSD

$\mathrm{PB}$, $\mathrm{GH}$, CSCD, GIA

RSD, SMSD,

GIA, DID, Fvr

ED, GH, DID,

GIA, GUA

Fvr, SMSD, ENT

GIA, GUA

ED, SMSD

DID, GUA ENT 
213 Senna tora (L.) Roxb.

Fabaceae

214 Sida acuta, Burm.f.

215

Sida alnifolia, L.

216 Sida cordifolia L.

217 Sida rhomboidea Roxb.exfleming.

218

219 Solanum nigrum L.

Solanum torvum SW.
Leaves, seeds

Leaves are purgative, used in ringworm and other skin troubles. Seeds used in leprosy, hemiplegia, skin diseases, constipation, abdominal disorders, obesity and helminthiasis.

Roots, leaves, Root is astringent, cooling, useful in nervous and urinary seeds

\section{diseases, Disorder of blood and bile. Leaves are} demulcent, diuretic.

CA, SMSD,

Used for rheumatism, neurological disorders, general debility, headache, ophthalmia, tuberculosis, diabetes, SMSD, ENT, fever, uterine disorders. It is also promote strength, Fvr, ED, GUA imparts to the body.

Roots are astringent, diuretic tonic; infusion given in urinary troubles, cystitis, haematuria, rheumatism, neurological disorders. Leaves demulcent and febrifuge; also used in dysentery.

The stems are used to treat rheumatism and tuberculosis.

Stem, leaves, The mucilaginous leaves are used as a demulcent and roots their stem and roots are used in treatment of wounds and leg ulcers in folkloric medicine.

Bark and oil is used in the treatment of malaria, ulcer, burns and scald.

The plant used in the treatment of asthma, vomiting, dropsy, rat bite and hydrophobia.

Bark, oil

Whole plant

Fruit, leaves

Part used and uses are similar to "Brihati".It is useful in liver as well as spleen enlargement.

Roots, flower

The flower heads are chewed to relieve the toothache and other mouth related troubles. leaves are used externally in treatment of skin diseases. Root decoction is used as
SMSD, DID

Fvr, GIA, DID

RSD, PB

LP,

DC, DID 
Stachytarpheta jamaicensis ( L.)Vahl.

230 Terminalia arjuna (DC.)Wight \& Arn.

Sterculia villosa Roxburg.

Strobilanthes heyneanus Nees.

Strobilanthus ciliates Nees.

Strychnos nux-vomica L.

Syzygium munronii (Wight.)

\section{Thottea siliquosa (Lam.)Ding} Hou.

Thunbergia alata ,Boj.ex Sins.

Thunbergia erecta Boj.
Myrtaceae

Verbenaceae

Combretaceae

Combretaceae

Fruit

Aristolochiaceae

Roots

Acanthaceae

Leaves

Root, bark, leaves, fruits

Whole plant

Bark,

Whole plant

Whole plant

Bark, leaves, seeds

Twigs

Bark,

wood

leaf,

Wood, bark,

stem

Acanthaceae purgative, diuretic and lithotriptic

The roots are useful in regulating menstruation, Bark is aromatic, astringent useful in dysentery, diarrhoea, vomiting and muscular rheumatism. Fruit is antiscorbutic and the pulp astringent used in bilious dyspepsia.

Whole plant is used for intestinal worms, venereal diseases, purulent, ulcers, dropsy, stomach ailments, vomiting, fevers and rheumatic inflammations.

The bark yields a strong fiber used for rough cordage and the cortex yields a white gum.

The ethanolic extract of whole plant is known to possess anti-diabetic, anti-implantation, estrogenic and antibacterial activities

Decoction of the whole plant used in the treatment of tooth problem.

The root bark is useful in cholera. Leaves are applied as poultice in treatment of chronic wounds and ulcers. Seeds are bitter, acrid, useful in anaemia and asthma.

The twigs are used against toothache. Twigs are also used in match box and plywood industries.

Bark and leaf is used in the treatment of hyper acidity, indolent ulcers, arthritis and eczema. Wood is also used to making furniture.

The wood is used for carts and agricultural implements. Powdered bark is used as appetizer. Stem bark paste is used as an ointment for wounds.

Fruit used in the treatment of tridosa, wounds, skin

diseases, cardiac disorders and cough. Fruits are

powdered and used for preventing cough and fever. Used as an appetizer.

Roots are used in ulcers, gonorrhea, leprosy, fever, cholera, rheumatism and antidote to snake-venum.

The plant mainly used as an ornamental plant. Leaves is used as infusion (internal and external).

It is used in detoxification as the first-aid. Seeds used as
GUA,

GIA, GUA Fvr, SMSD

DC
DC

GIA, DID

GIA, DID

DID, CSCD,

RSD, Fvr

GIA

GIA, Fvr SMSD, PB

CSCD

DID 


\section{Uvaria narum,(Dunal)}

Tridax procumbens L.

Vateria indica, L.

Vatica chinensis, L.

Vernonia cinerea, (L.) Less.

Vitex negundo L.

Wedelia chinensis

(Osbeck)Merr.

Zanthoxylum rhetsa DC.

\section{Tragia involucrate L.}

Triumfetta rhomboidea Jacq.

Vanda tessellata (Roxb.)Hook.

Vigna $\quad$ dalzellliana,(0.Kzte)
Verdc.
Tiliaceae

Malvaceae

Annonaceae

Asteraceae

Fabaceae

Menispermaceae

Scrophulariaceae

Euphorbiaceae

Asteraceae

Lea

Roots, bark,

leaves, flower

Roots

Root bark, leaves, stem

Root

Dipterocarpaceae Plant resin

Dipterocarpaceae Stem

Verbenaceae

Asteraceae

Rutaceae

Whole plant

Whole plant purgative.

Stem, leaf, Stem extract is used in fevers. Stem also used for severe mouth ulcers. Leaf decoction when consumed relieve gas problem. Root is prescribed in diarrhoea and diabetes.

Whole plant is used as an exanthematic ointment. Leaves are used in gonorrhoea

The leaves and stem paste is applied to arrest skin diseases.

Leaf juice is applied on cuts and wounds as antiseptic and to stop bleeding.

Root is used in dysentery, intestinal ulcers. Bark and leaves are used in diarrhoea. Leaves and flowers are used in leprosy.

Roots are used as folk and siddha medicine.

Fvr, DID

DID

GIA

Decoction of root bark is given to women at the time of

GUA, SMSD,

complaints and eczema. Leaves prescribed in DID, LP, GIA rheumatism, jaundice. Stem is used for gastropathy.

Roots paste is applied one in a day for 5-6 days for rheumatism.

Plant resin burnt for incense, used in varnish,water proofing; essential oil as antibacterial.

A yellow transparent resin exudes from the stem is used

in the manufacture of varnishes. Wood reddish brown used for building piles.

The plants are bitter, acrid, thermogenic, antivitral, anthelmintic, antifungal. The roots are useful in diarrhoea, inflammations and skin diseases.

It is used as food and drink. It is also sometimes grown for soil conservation.

A decoction is used for steam bath for arthritis and joint

pains. Root, leaf and flower is used in the treatment of malarial fever, sprains, odontalgia and otalgia.

Leaf tonic is used in cough, cephalalgia and alopecia.

Decoctions of whole plant are useful in inflammation, otalgia, ulcers, baldness and greyness of hair.

GIA, HC,

SMSD

Bark, fruits, Bark and fruits are used in dyspepsia, asthma, bronchitis, GIA, 
*CSCD - Circulatory system / cardiovascular diseases; CA - Cooling agent; DC - Dental care; ENT - Ear, nose, throat problems; DID - Dermatological infections / diseases; ED - Endocrinal disorders; Fvr - Fever; GIA - Gastro-intestinal ailments; GH- General health; GUA - Genito-urinary ailments; HC - Hair care; LP - Liver problem; PB - Poisonous bite; RSD - Respiratses; SMSD - Skeleto-muscular system disorder; IC - Insecticidal.

Table 2. Ailment categories included with various ailments.

\begin{tabular}{|c|c|c|c|}
\hline S. No. & Ailment categories & Biomedical terms & Tamil terms \\
\hline \multirow[t]{4}{*}{1.} & Circulatory system/ & Blood purification & Rattha sutthigarippu \\
\hline & cardiovascular diseases (CSCD) & Memory power & Gnabaga sakthi \\
\hline & & Heart problem & Idhaya noi \\
\hline & & Hypotensive & Rattha alutta noi \\
\hline 2. & Cooling agent (CA) & Body coolant & Udal kulircchi \\
\hline 3. & Dental care (DC) & Tooth ache & Pal vali \\
\hline \multirow[t]{8}{*}{4.} & Dermatological & Wound healing & Kaayam \\
\hline & infections/diseases (DID) & Skin diseases & Thol noi \\
\hline & & Antiinflammatory & Alargi etirppu \\
\hline & & Antioxidant & \\
\hline & & Scabies & Sori/sirangu \\
\hline & & Antiseptic & Kirumi nacini \\
\hline & & Eczema & Thol alargi \\
\hline & & Itching & Arippu/poocchikadi \\
\hline \multirow[t]{2}{*}{5.} & Ear, nose, throat problems (ENT) & Eye pain & Kan vali \\
\hline & & Ear pain & Kathu vali \\
\hline \multirow[t]{4}{*}{6.} & Endocrinal disorders (ED) & Diabetes & Sarkkarai/neerilivu noi \\
\hline & & Kidney stone & Siruneeraga kal \\
\hline & & Urinary problem & Siruneeraga noi \\
\hline & & Cystitis & Siruneerpai alargi \\
\hline \multirow[t]{3}{*}{7.} & Fever (Fvr) & Fever & Kaichal \\
\hline & & Pneumonia & Jani \\
\hline & & Malaria & Murai/malaria kaichal \\
\hline \multirow[t]{3}{*}{8.} & Gastro-intestinal ailments (GIA) & Ulcer & Vayitru pun \\
\hline & & Stomachache & Vayitru vali \\
\hline & & Carminative & Iraippai kuțal vali \\
\hline
\end{tabular}


9. General health (GH)

10. Genito-urinary ailments (GUA)
11. Hair care (HC)
12. Liver problem (LP)
13. Poisonous bite (PB)

14. Respiratory system diseases (RSD)

15. Skeleto-muscular system disorders (SMSD)

Gastric complaints
Digestion/indigestion
Dysentery
Dyspepsia
Diarrhea
Cholera
Vermifuge
Intestinal worms
Appetite
Piles
Tonic
Constipation
Depression
Insomnia
Obesity
Delivery pain
Menstrual problem
Abortion
Male fertility
Venereal diseases
Galactagogue
Sexual problem
Hair tonic
Jaundice
Liver infection
Snake bite
Dog bite
Poisonous bite
Detoxification
Asthma
Chest pain
Cold
Cough
Expectorant
Bronchitis
Haemoptysis
Rheumatism
Arthritis
Joint pain

Vayvu kolaru

Geeranam/ageeranam

Seedhabaethi

Cerimanaminmai

Vayirrup pokku

Kalara

Pulukkolli

Kutal pulukkal

Paciyinmai

Mula noi

Sathu marunthu

Malaccikkal

Mana aluttam

Tukkaminmai

Udal paruman

Pirasava vali

Matavitay thontharavugal

Karu kalaipu

Anmai sakthi perukkuthal

Paalvinai noi

Thaai pallai urpathi pana

Paliyal piraccanai

Mudi valara

Manajal kaamalai

Kaleral thotru

Pambukkadi

Naikkadi

Vishakkadi

Nachu neeka

Moocchu thinaral

Nenju vali

Jalathosam

Irumal

Sali

Muccukkulay alarci

Suvacakkulaliruntu irattam varuthal

Moottu vadham

Kilvatam

Moottu vali 


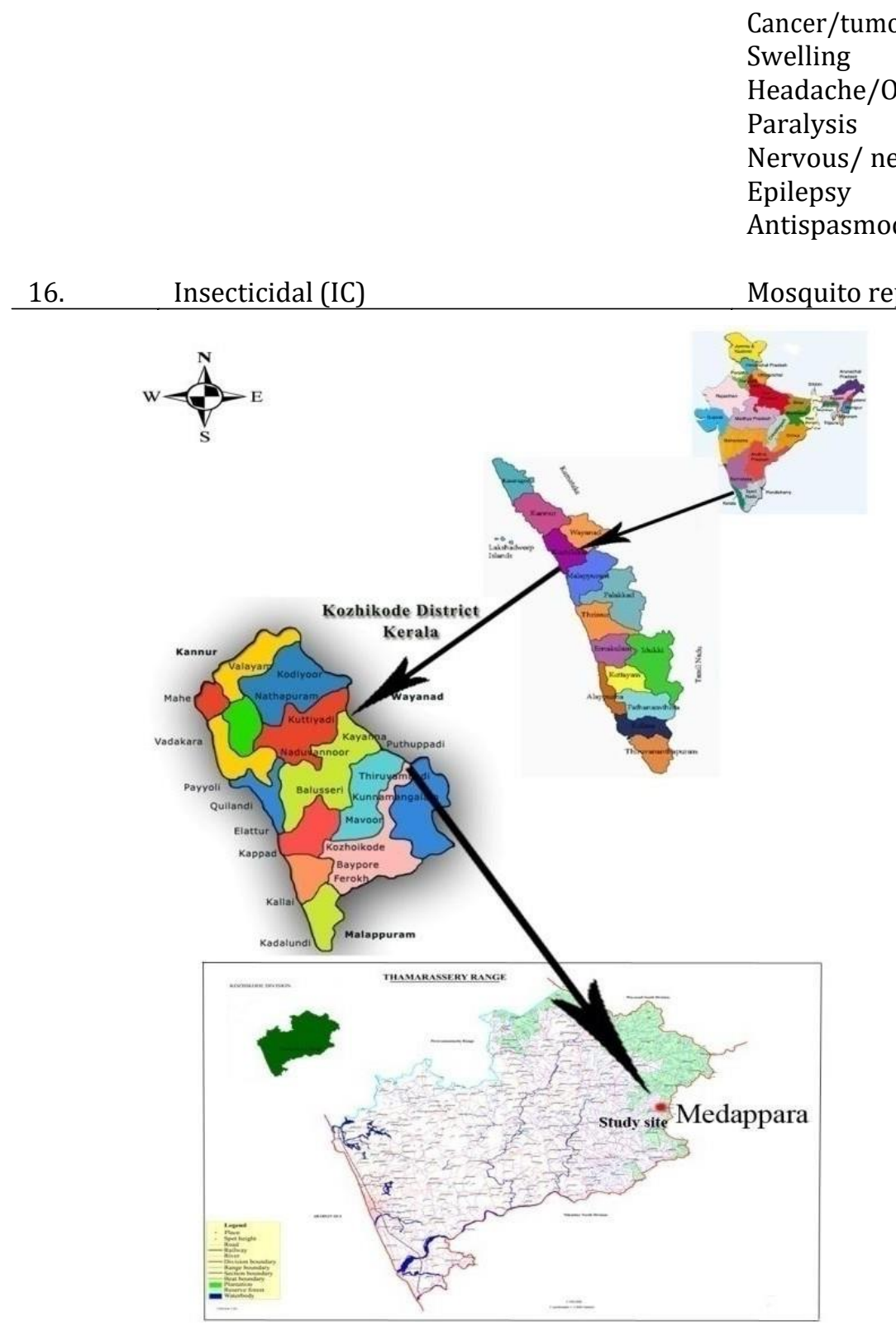

Putru noi

Veekam

Thalai vali/oru paka thalai vali

Pakavatam

Narambu pathipu

Epilepsy

Antispasmodic

Kaka valipu

Valipu

Kosuviratti

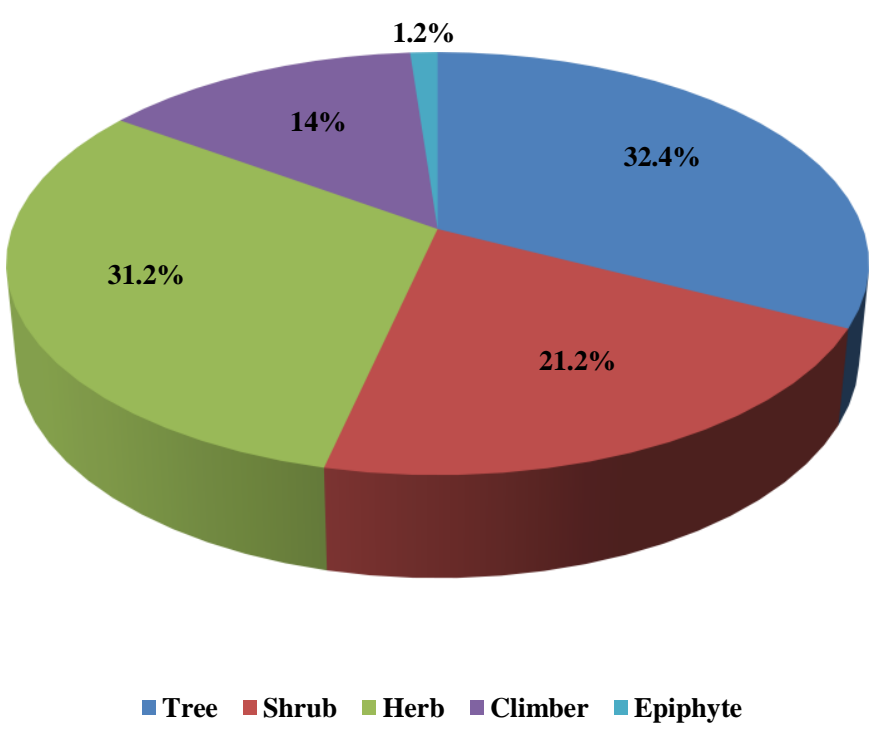

Fig. 2. Pie chart showing the percentage contribution of various life forms in the studied forest at Medappara, Kerala.

Fig. 1. Location of the study area 
It enables us to work with local people to explore knowledge based on experiences and ages. The indigenous population still relies to a great extent on traditional healers and medicinal plants to meet their healthcare needs because of the perceived effectiveness, presumed safety with minimal side effects and affordability (Vliathan, 1998). Of the 16 ailment categories analyzed, a higher number of 110 , 86 and 82 species were prescribed for Gastro Intestinal Ailments (GIA), Dermatological Infection (DID) and Muscular System Disorder (SMSD) respectively. It may be explained due to the presence of the respective bioactive compounds in the secondary metabolites produced by the species (Ayyanar and Ignacimuthu, 2011). It has been noted interestingly that a very little number of 2 species viz., Cycas circinalis and Duranta erecta were used for insecticidal property and also as mosquito repellent species. The presence of certain alkaloids may be the possible reason for this fact (Mayura and Phasomkusolsil, 2014).

The medicinal uses of plants gathered in the present study were compared with the previously published information from other parts of India. It showed that no plants were reported as a new medicinal plant as all the plants were reported with different uses. This fact exhibits that the medicinal plants enlisted in the study area are already prescribed by the healers of various areas in India. When the life-form is considered, higher number of species used for various ailments were trees. It may be explained that the studied forest at Medappara is a climax formation (Champion, 1939) and contains the trees as dominant and most established structures which might aid the sources of medicine consistently. Gonzalez et al. (2010) also reported the usage of more tree species for medicinal purpose in the climax forest in the western Spain due to its stable structure and consistency in availability. Among the different plant parts used, the leaves were most frequently used for medicinal purposes. Many indigenous communities elsewhere also utilized mostly leaves for the medicinal purposes (Ignacimuthu et al., 2006, 2008; Teklehaymanot et al., 2007; Srithi et al., 2009; Giday et al., 2010; Cakilcioglu and Turkoglu, 2010; Gonzalez et al.,2010 and Abdul Latheef et al., 2014). The reason why leaves were used mostly is that they are collected very easily than underground parts, flowers, fruits etc. (Giday et al., 2009) and in scientific point of view leaves are active in photosynthesis and production of metabolites (Ghorbani, 2005).

\section{CONCLUSION}

The present study indicated that the study area has numerous medicinal plants to treat a wide range of human ailments. Studies on traditional medicinal plants revealed that the local people from medappara forest prefer traditional medicine due to low cost and sometimes it is a part of their social life and culture so it is necessary to acquire and preserve this traditional system of medical practice. Further, studies by using animal models and subsequent clinical trials are suggested to confirm the traditional knowledge on medicinal plants, thus used for drug manufacturing by pharmaceutical industries.

\section{REFERENCES}

Abdul Latheef, K., P. Smitha Kumar and A.B. Remashree, (2014). Ethnomedicine used for treating cuts and wounds by the tribes of Attapady, Kerala. Int. J. Herbal Med. 2(2): 1-8.

Abraham, Z. (1981). Ethnobotany of Todas, the Kotas and the Irulas of Nilgiris: Glimbses of Indian Ethnobotany, New Delhi: Oxford and IBH Publishing Co. p. 308-320.

Awadh, A., N. Ali, I.K. Al-rahwi and U. Lindequist. (2004). Some medicinal plants used in Yemeni herbal medicine to treat Malaria. Afr. J. Trad. Comp. Alt. Med. 1: 72-76.

Ayyanar, M. and S. Ignacimuthu, (2011). Ethnobotanical survey of medicinal plants commonly used by Kani Tribals in Tirunelveli Hills of Western Ghats, India. J. Ethnopharmacol. 134: 851-864.

Cakilcioglu, U. and I. Turkoglu, (2010). An ethnobotanical survey of medicinal plants in Sivrice (Elazig-Turkey). J. Ethnopharmacol. 132: 165-175.

Champion, H.G., (1939). The relative stability of Indian vegetational types. J. Ind. Bot. Soc. 18:1.

Diallo, D., B. Hveem, M.A. Mahmoud, G. Berge, B.S. Paulsen and A. Maiga, (1999). An ethnobotanical survey of herbal drugs of Gourma district, Mali. Pharma Biol. 37: 80-91.

Gamble, J.S. and C.E.C. Fisher, (1957). Flora of the Presidency of Madras. Vols. 1-3. London: Adlard and Sons Ltd, Calcutta, India, p. 1915-1936

Ghorbani, A. (2005). Studies on pharmaceutical ethnobotany in the region of Turkmen Sahra, north of Iran (Part 1): general results. J. Ethnopharmacol. 102: 58-68. 
Giday, M., Z. Asfaw and Z. Woldu (2010). Ethnomedicinal study of plants used by Sheko ethnic group of Ethiopia. J. Ethnopharmacol. 132: $75-85$.

Giday, M., Z. Asfaw and Z. Woldu, (2009). Medicinal plants of the Meinit ethnic group of Ethiopia: an ethnobotanical study. J. Ethnopharmacol. 124: 513-521.

Gonzalez, J.A., M. Garcia-Barrriuso and F. Amich, (2010). Ethnobotanical study of medicinal plants traditionally used in the Arribes del Duero, Western Spain. J. Ethnopharmacol. 131: 343-355.

Heinrich, M., (2000). Ethnobotany and its role in drug development. Phytotheraphy Res. 14: 479488.

Ignacimuthu, S., M. Ayyanar and K. Sankarasivaraman, (2006). Ethnobotanical investigations among tribes in Madurai district of Tamil Nadu, India. J. Ethnobiol. Ethnomed. 11: 2.

Ignacimuthu, S., M. Ayyanar and K. Sankarasivaraman, (2008). Ethno-botanical study of medicinal plants used by Paliyar tribals in Theni district of Tamil Nadu, India. Fitoterapia 79: 562-568.

Jain, S.K. and A.K. Goel, (1995). A manual of Ethnobotany. Jodhpur, India: Scientific Publishers, p. 142-153.

Jain, S.K., (1989). Methods and Approaches in Ethnobotany. Lucknow, India: Society of Ethnobotany.

Kunwar, R.M. and N.P.S. Duwadee, (2003). Ecology and Economy of NTFP's in Nepal: A case study from Dolpa and Jumla districts, Nepal. Botanica Orientalis 3: 89-97.

Mathew, K.M. (1983). The Flora of Tamilnadu Carnatic, the Rapinat Herbarium, St. Josephs College, Tiruchirapalli, India.

Mayura, S. and S. Phasomkusolsil, (2014). Mosquito repellent from Thai essential oils against dengue fever mosquito (Aedes aegypti L.) and filarial mosquito vector (Culex quinquefasciatus Say). Afr. J. Microbiol. Res. 8(17): 1819-1824.

Parthasarathy, J., (1995). Nilgiri Tribes Towards Plantation Economy. The Planters Chronicle (KVK Special) UPASAI: Coonoor; p. 162-163.
Perumalsamy, R. and S. Ignacimuthu, (2000). Antibacterial activity of some of folklore medicinal plants used by tribals in Western Ghats of India. J. Ethnopharmacol. 69: 63-71.

Pradheeps, M. and G. Poyyamoli, (2013). Ethnobotany and utilization of plant resources in IrulaVillages (Sigur Plateau, Nilgiri Biosphere Reserve, India). J. Med. Pl. Res. 7(6): 267-276.

Rajan, S., M. Jayendran and M. Sethuraman, (2003). Medico-ethnobotany; A study on the Kattunayaka tribe of Nilgiri Hills, Tamil Nadu. J. Nat. Remed. 3(1): 68-72.

Sahai, S., (2003). Importance of Indigenous Knowledge. Ind. J. Trad. Knowled. 2(1): 11.

Schultes, R.E., (1962). The role of the ethnobotanist in search for new medicinal plants. Lloyida, 25(4): 257-266.

Sharmila, S., K. Kalaichelvi and M. Rajeswari, (2014). Certain Endemic and Ethnobotanically important Plants of Thiashola, Manjoor, Nilgiris South Division, Western Ghats. Int. J. Pharmaceu. Sci. Rev. Res. 27(2): 314-318.

Siddhiqui, M.A.A., A.G. John and T.M. Paul, (1995). Status of some important medicinal and aromatic plants of Kashmir Himalaya. Adv. Pl. Sci. 8: 134-139.

Sivakumar, A. and M. Murugesan, (2005). Ethnobotanical studies on the wild edible plants used by the tribals of Anaimalai Hills, The Western Ghats. Ancient Sci. Life 25(2): 69-73.

Srithi, K., H. Balslev, P. Wangpakapattanawong, P. Srisanga and C. Trisonthi, (2009). Medicinal plant knowledge and its erosion among the Mien (Yao) in northern Thailand. J. Ethnopharmacol. 123: 335-342.

Teklehaymanot, T., M. Giday, G. Medhin and Y. Mekonnen, (2007). Knowledge and use of medicinal plants by people around Debre Libanos monastery in Ethiopia. J. Ethnopharmacol. 111: 271-283.

Venkatachalapathi A., S. Paulsamy and J. Thambiraj, (2016). Antimicrobial efficacy of the ethnomedicinal plant species, Canarium strictum Roxb. Int. J. Pharm. Pharmaceu. Sci. 8(2): 339-341.

Vliathan, M.S., (1998). Healing plants. Curr. Sci. 75: 1122-1126. 